\title{
Analisis Mikrostruktur thin film ZnO pada Si dan thin film ZnO pada $\mathrm{Cu}$
}

\author{
Affi Nur Hidayah* dan Maria M. Suliyanti \\ Pusat Penelitian Fisika - LIPI, Kawasan PUSPIPTEK, Serpong, \\ Tangerang Selatan 15314 Banten
}

\begin{abstract}
Intisari
Telah dilakukan analisa mikrostruktur dari thin film $\mathrm{ZnO}$ pada substrat $\mathrm{Si}$ dan $\mathrm{Cu}$. thin film dibentuk dengan menggunakan teknik berbasis laser yang dikenal dengan Pulsed Laser Deposition (PLD). Laser yang digunakan dalam pembentukan thin film adalah laser Nd-YAG pulsa dengan panjang gelombang $532 \mathrm{~nm}$, energi $75 \mathrm{~mJ}$ dan frekuensi $10 \mathrm{~Hz}$. Substrat ( $\mathrm{Si}$ dan $\mathrm{Cu}$ ) dan sampel (pelet $\mathrm{ZnO}$ ) diletakkan pada ruang vakum pada tekanan 5 Torr, dengan iradiasi laser selama 5 menit (3000 shoots). thin film yang dihasilkan berbentuk lapisan-lapisan seperti pelangi dengan bagian tengah berwarna putih. thin film kemudian dikarakterisasi dengan menggunakan SEM EDX pada tiga titik yang berbeda yaitu titik tengah, titik kiri dan titik kanan. Hasil SEM menunjukkan bahwa thin film mempunyai lapisan $\mathrm{ZnO}$ tidak merata. Hasil lapisan menunjukkan lapisan paling banyak dibagian tengah yang berwarna putih dibandingkan di bagian kiri dan kanan. Dimana prosentase massa Si dibagian tengah $0 \%$, Zn $(31,33 \%)$ dan massa O (20,56\%). Sedangkan prosentase massa Si dibagian kiri $(82,1 \%)$ lebih besar dibandingkan massa $\mathrm{Zn}(3,81 \%)$ dan massa O (8,6\%). Dan pada titik kanan komposisi Si juga lebih besar dengan massa $(83,26 \%)$ dibandingkan $\mathrm{Zn}(3,55 \%)$ dan massa O $(8,38 \%)$. Hal yang sama juga ditunjukkan pada lapisan $\mathrm{ZnO}$ pada substrat $\mathrm{Cu}$. Dimana prosentase massa $\mathrm{Cu}$ dibagian tengah lebih kecil $(5,39 \%)$ dibandingkan prosentase massa $\mathrm{Zn}(40,66 \%)$ dan massa O $(16,66 \%)$. Sedangkan pada titik kiri prosentase massa Cu lebih besar $(91,43 \%)$ dibandingkan massa Zn $(1,8 \%)$ dan massa O $(3,81 \%)$. Dan pada titik kanan massa Cu memilki prosentase lebih besar $(81,59 \%)$ dibandingkan massa $\mathrm{Zn}(2,61 \%)$ dan massa O $(4,82 \%)$.
\end{abstract}

KATA KUNCI: thin film ZnO, PLD, mikrostruktur lapisan, SEM EDX

\section{PENDAHULUAN}

Pembentukan thin film $\mathrm{ZnO}$ (Zinc Oxide) akhir-akhir ini menjadi subjek dari penelitian yang menarik. Daya tarik penelitian ini karena $\mathrm{ZnO}$ merupakan material yang potensial untuk aplikasi-aplikasi yang berbeda pada optik, listrik, piezoelektrik, peralatan optoelektronika $[1,2]$ dan lainnya. $\mathrm{ZnO}$ merupakan senyawa anorganik yang biasanya berbentuk serbuk putih, hampir tidak larut dalam air. Serbuk ini secara luas digunakan sebagai zat aditif ke dalam berbagai bahan dan produk yang meliputi plastik, keramik, kaca, semen, karet (misalnya, ban mobil), pelumas, cat, salep, lem, baterai, dan lainnya [3]. Di dalam ilmu material $\mathrm{ZnO}$ merupakan semikonduktor II-IV yang memiliki banyak keunggulan yaitu sifat transparansi yang baik, mobilitas elektron tinggi, celah pita lebar (3.37 eV atau $375 \mathrm{~nm}$ pada suhu ruang), luminescence yang kuat pada suhu ruang [4]. Karena keunggulan inilah $\mathrm{ZnO}$ banyak digunakan pada bidang elektronika dan optoelektronika pada laser diode, LED (Light Emitting Diode) [5], LCD (Liquid Crystal Display), aplikasi sel surya [6] dan juga sebagai biosensor [7].

Perlu sekali untuk menumbuhkan thin film $\mathrm{ZnO}$ yang berkualitas bagus pada substrat yang banyak digunakan sebagai material elektronik, contohnya yaitu Silicon dan Tembaga (Copper). Silicon umumnya metalloid yang merupakan

\footnotetext{
*E-MAIL: affi001@lipi.go.id
}

semikonduktor. Silikon mempunyai kristal tunggal. Silikon murni mempunyai warna abu-abu dan mengkilap, mirip dengan kaca tetapi lebih kuat, sangat rapuh dan rentan patah [8]. Sedangkan Tembaga ( $\mathrm{Cu}$ ) merupakan logam yang elastik yang mempunyai konduktivitas listrik dan termal yang tinggi. Dibidang elektronika $\mathrm{Cu}$ banyak digunakan sebagai kawat tembaga, elektromagnet, relay, busbar dan switch listrik. Dan juga untuk pembuatan $\mathrm{PCB}$, bahan pembuat heat sink komputer, tabung vakum, tabung sinar katoda dan sebagai magnetron pada microwave [9].

Banyak teknik yang digunakan untuk pembentukan thin film $\mathrm{ZnO}$. Teknik pembentukan thin film yang menggunakan teknologi laser dikenal sebagai PLD, dimana material diuapkan dan dilepas dari permukaan target sebagai cahaya dari sebuah laser yaitu plasma. Film dibentuk dengan pemadatan material yang diablasikan dari target ke substrat.

Karakteristik-karakteristik penyerapan dari material yang di uapkan bergantung pada panjang gelombang yang digunakan [10]. Pada umumnya standar laser yang digunakan PLD adalah laser excimer dan laser Nd YAG, yang mana dengan laser tersebut telah didemonstrasikan berbagai keuntungan teknik deposisi film, termasuk set-up yang sederhana, kecepatan deposisi yang tinggi, kontaminasi yang rendah dan transfer stoikiometri material dari target ke film. Dengan frekuensi yang sangat tinggi memungkinkan penumbuhan film berkualitas sangat tinggi dengan kecepatan yang tinggi [11]. 


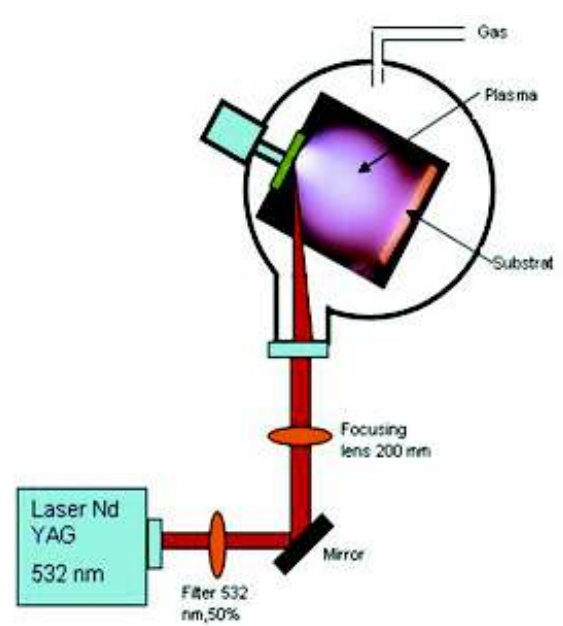

Gambar 1: Set-up laser Nd-YAG

\section{METODOLOGI PENELITIAN}

Proses pembentukan thin film dimulai dengan pembuatan pellet target $\mathrm{ZnO}$ dari serbuk $\mathrm{ZnO}$, dilanjutkan dengan pemotongan substrat silicon sheet dan $\mathrm{Cu}$. Penumbuhan lapisan tipis $\mathrm{ZnO}$ pada substrat $\mathrm{Si}$ dan $\mathrm{Cu}$ dibentuk dengan menggunakan teknik PLD. Laser yang digunakan adalah laser NdYAG second harmonic dengan panjang gelombang $532 \mathrm{~nm}$ Quanta-Ray Spectra-Physics, energi $75 \mathrm{~mJ}$ dan frekuensi 10 Hz. Set-up eksperimen yang digunakan ditunjukkan pada Gambar 1. Berkas Laser difokuskan pada target $(\mathrm{ZnO})$ dengan sudut $45^{\circ}$ yang akan membentuk plasma. Didepan target diletakkan substrat pada arah paralel dengan jarak sekitar 2 $\mathrm{cm}$. Target dan substrat diletakkan pada ruang vakum yang dilengkapi dengan pirani meter untuk memonitor tekanan pada ruang vakum dan diatur tekanan sampai 5 Torr.

Kemudian atom-atom dan ion yang diablasikan dari target di deposisikan pada substrat, iradiasi dilakukan selama 5 menit (3000 shoots).

Setelah thin film $\mathrm{ZnO}$ dibentuk, maka sampel di karakterisasi dengan SEM EDX. Karakterisasi SEM dilakukan pada tiga titik yang berbeda pada lapisan thin film. Pengambilan di titik-titik yang berbeda bertujuan untuk mengetahui keseragaman dan perataan lapisan (kehomogenan) lapisan thin film yang dihasilkan. Pengambilan titik-titik lapisan thin film $\mathrm{ZnO}$ pada substrat Si dan Cu ditunjukkan pada Gambar 2.

\section{HASIL DAN DISKUSI}

Dari hasil pembentukan film kemudian dilakukan karakterisasi mikrostruktur lapisan thin film dengan menggunakan SEM EDX yang diambil dengan tiga perbesaran yang berbeda yaitu 1000X, 7500X dan 20000X. Hasil karakterisasi mikrostruktur lapisan $\mathrm{ZnO}$ pada substrat Si ditunjukkan pada Gambar 3 dan prosentase komposisi lapisan $\mathrm{ZnO}$ ditunjukkan pada Tabel 1 .

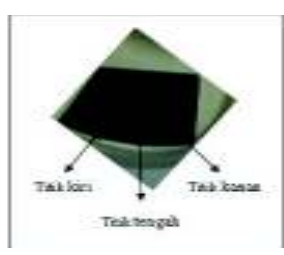

(a)

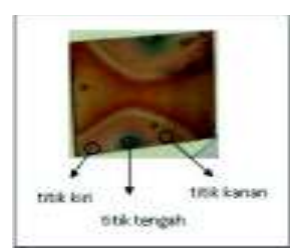

(b)
Gambar 2: Tiga titik thin film $\mathrm{ZnO}$ yang diambil pada(a) substrat $\mathrm{Si}$ dan(b)substrat $\mathrm{Cu}$

TABEL I: Hasil prosentase komposisi lapisan thin film $\mathrm{ZnO}$ pada $\mathrm{Si}$ dengan menggunakan SEM EDX.

\begin{tabular}{|c|c|c|c|c|c|c|}
\hline & Elemen & $(\mathrm{keV})$ & Mass \% & Error\% & Atom $\%$ & K \\
\hline \multirow[t]{2}{*}{ Titik tengah } & O K & 0,525 & 20,56 & 0,19 & 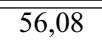 & $\overline{13,926}$ \\
\hline & $\mathrm{Zn} \mathrm{K}$ & 8,63 & 31,33 & 0,54 & 20,91 & 39,8519 \\
\hline \multirow[t]{3}{*}{ Titik kiri } & $\mathrm{O} \mathrm{K}$ & 0,525 & 8,6 & 1,31 & 15,02 & 5,1765 \\
\hline & Si K & 1,739 & 82,1 & 0,43 & 81,67 & 88,4922 \\
\hline & $\mathrm{Zn} \mathrm{K}$ & 8,63 & 3,81 & 4,36 & 1,63 & 3,6551 \\
\hline \multirow[t]{3}{*}{ Titik kanan } & $\mathrm{OKK}$ & 0,525 & 8,38 & 1,26 & 14,56 & 4,9984 \\
\hline & Si K & 1,739 & 83,26 & 0,41 & 82,46 & 89,3259 \\
\hline & $\mathrm{Zn} \mathrm{K}$ & 8,63 & 3,55 & 4,23 & 1,51 & 3,3631 \\
\hline
\end{tabular}

Pada Gambar 3 menunjukkan mikrostruktur lapisan thin film $\mathrm{ZnO}$ pada Si dimana Gambar 3a (titik tengah lapisan) menunjukkan lapisan $\mathrm{ZnO}$ menutupi permukaan substrat Silicon, sedangkan Gambar 3b (titik kiri lapisan) dan Gambar 3c (titik kanan lapisan) menunjukkan bahwa lapisan $\mathrm{ZnO}$ tidak semuanya menutupi substrat Si. Hasil ini juga ditunjukkan pada Tabel 1, dimana pada titik tengah komposisi massa $\mathrm{Si}$ tidak terlihat (0\%), Zn (31,33\%) dan massa O (20,56\%), yang berarti bahwa substrat Si sudah tertutup oleh lapisan $\mathrm{ZnO}$.

Sedangkan pada titik kiri komposisi Si lebih besar dengan massa $(82.1 \%)$ dibandingkan $\mathrm{Zn}(3,81 \%)$ dan massa $\mathrm{O}$ $(8,6 \%)$. Dan pada titik kanan komposisi Si lebih besar dengan massa $(83,26 \%)$ dibandingkan $\mathrm{Zn}(3,55 \%)$ dan massa $\mathrm{O}$ $(8,38 \%)$. Hal ini menunjukkan bahwa lapisan $\mathrm{ZnO}$ yang terbentuk pada substart Si mempunyai lapisan paling tebal dan merata di daerah tengah, sedangkan pada daerah kiri dan kanan yang berbentuk pelangi menandakan bahwa lapisan $\mathrm{ZnO}$ yang dihasilkan sangat tipis.

Sedangkan hasil karakterisasi mikrostruktur lapisan $\mathrm{ZnO}$ pada substrat $\mathrm{Cu}$ ditunjukkan pada Gambar 4 dan komposisi lapisan $\mathrm{ZnO}$ pada $\mathrm{Cu}$ ditunjukkan pada Tabel 2.

Gambar 4a menunjukkan mikrostruktur hasil lapisan $\mathrm{ZnO}$ pada substrat $\mathrm{Cu}$ yang berada pada titik tengah. Dari Gambar 4a dapat dilihat bahwa lapisan $\mathrm{ZnO}$ merata dan menutupi substrat $\mathrm{Cu}$ dengan bentuk lapisan seperti tumpukan batu. Sedangkan pada Gambar 4b (mikrostruktur lapisan pada titik kiri) menunjukkan bahwa lapisan $\mathrm{ZnO}$ yang terbentuk sedikit, tidak merata dan tidak menutupi keseluruhan substrat $\mathrm{Cu}$. Dan Gambar 4c (mikrostruktur lapisan $\mathrm{ZnO}$ pada titik kanan) menunjukkan lapisan $\mathrm{ZnO}$ yang terbentuk sedikit, tidak merata pada substrat $\mathrm{Cu}$. Untuk mengetahui nilai massa tiap komponen lapisan pada tiga titik yang berbeda ditunjukkan pada Tabel 2 yang merupakan hasil prosentase komposisi lapisan 


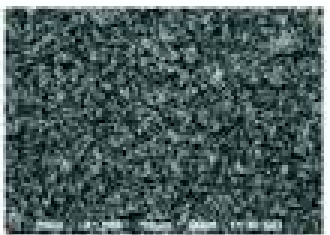

$1000 x$

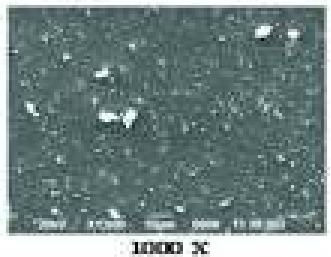

$1000 x$

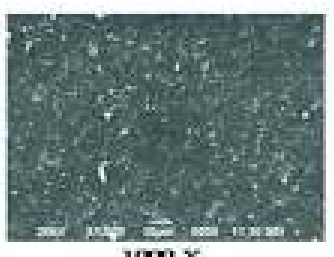

$\sin x$

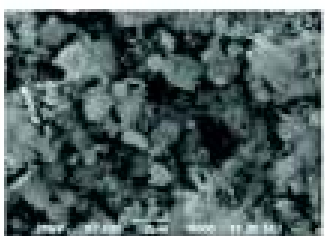

$7800 \times$

(a)

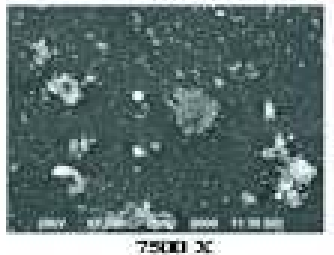

(b)

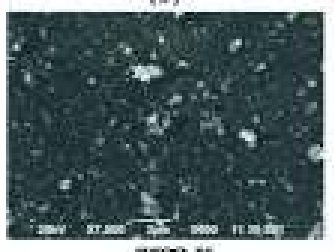

(c)

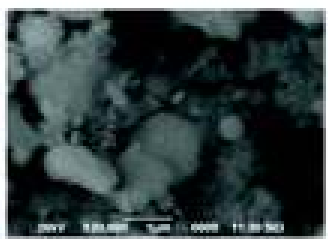

$20000 \times$

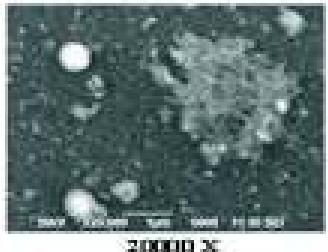

$2 \operatorname{con} x$

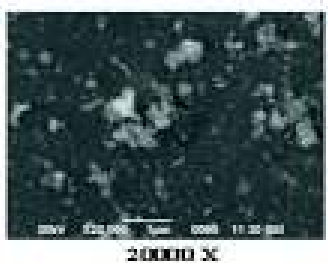

$20000 \mathrm{x}$

Gambar 3: Hasil mikrostruktur lapisan thin film ZnO pada Si (a) titik tegah, (b) titik kiri, dan (c) titik kanan

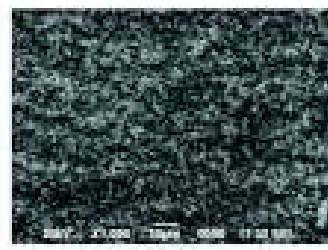

$1000 \mathrm{x}$

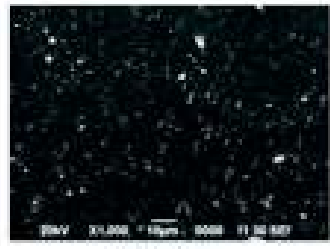

$1000 \mathrm{x}$

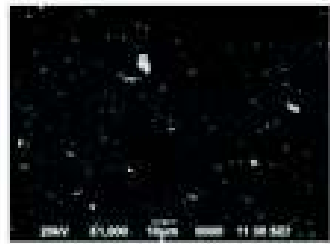

$1000 \mathrm{x}$

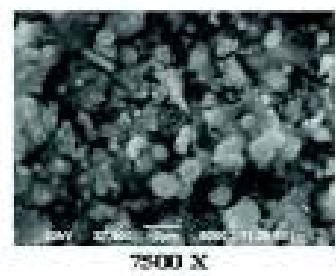

(a)

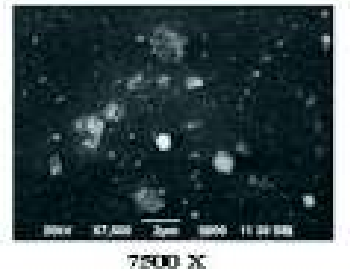

(b)

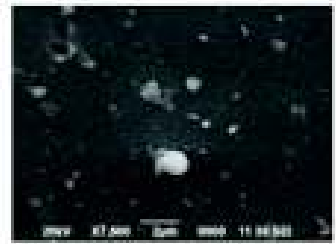

$7800 \mathrm{x}$
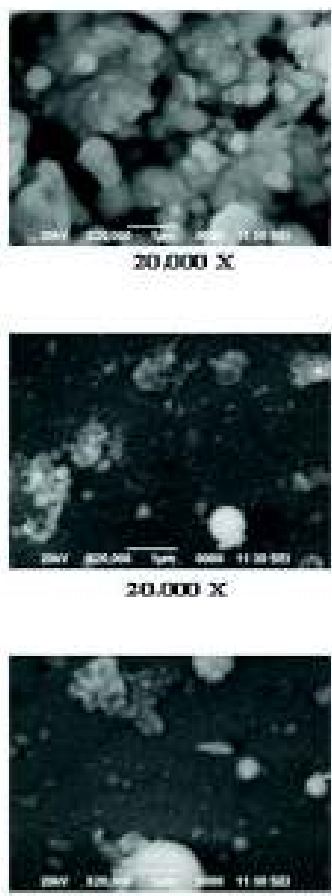

$20000 x$

(c)

Gambar 4: Hasil mikrostruktur lapisan thin film $\mathrm{ZnO}$ pada $\mathrm{Cu}$ (a) titik tegah, (b) titik kiri, dan (c) titik kanan 
TABEL II: Hasil prosentase komposisi lapisan thin film $\mathrm{ZnO}$ pada $\mathrm{Cu}$ dengan menggunakan SEM EDX.

\begin{tabular}{|c|c|c|c|c|c|c|}
\hline & Element & $(\mathrm{keV})$ & Mass $\%$ & Error\% & Atom $\%$ & $\bar{K}$ \\
\hline \multirow[t]{3}{*}{ Titik tengah } & $\mathrm{OK}$ & 0,525 & 16,65 & 0,15 & 48,25 & 12,2335 \\
\hline & $\mathrm{Cu} \mathrm{K}$ & 8,04 & 5,39 & 0,37 & 3,94 & 6,5307 \\
\hline & Zn K & 8,63 & 40,66 & 0,47 & 28,85 & 49,5632 \\
\hline \multirow[t]{3}{*}{ Titik kiri } & $\mathrm{OK}$ & 0,525 & 3,81 & 0,22 & 13,71 & 3,9201 \\
\hline & $\mathrm{Cu} \mathrm{K}$ & 8,04 & 91,43 & 0,92 & 82,84 & 92,5088 \\
\hline & Zn K & 8,63 & 1,8 & 1,18 & 1,59 & 1,8275 \\
\hline \multirow[t]{3}{*}{ Titik kanan } & $\mathrm{O} \mathrm{K}$ & 0,525 & 4,82 & 0,22 & 12,87 & 4,7198 \\
\hline & $\mathrm{Cu} \mathrm{K}$ & 8,04 & 81,59 & 0,82 & 54,9 & 89,1953 \\
\hline & Zn K & 8,63 & 2,61 & 1,05 & 1,71 & 2,8566 \\
\hline
\end{tabular}

thin film $\mathrm{ZnO}$ pada $\mathrm{Cu}$ dengan menggunakan SEM EDX. Pada Tabel 2 menunjukkan bahwa pada titik tengah, komposisi massa $\mathrm{Cu}$ paling kecil (5,39\%) dibandingkan prosentase massa $\mathrm{Zn}(40,66 \%)$ dan massa O $(16,66 \%)$. Sedangkan pada titik kiri prosentase massa $\mathrm{Cu}$ paling besar $(91,43 \%)$ dibandingkan massa $\mathrm{Zn}(1,8 \%)$ dan massa O (3,81\%). Dan pada titik kanan massa $\mathrm{Cu}$ memilki prosentase paling besar $(81,59 \%)$ dibandingkan massa $\mathrm{Zn}(2,61 \%)$ dan massa O (4,82\%). Dengan melihat hasil Gambar 4 dan Gambar 3 dapat diketahui bahwa lapisan $\mathrm{ZnO}$ yang dihasilkan baik pada substrat $\mathrm{Cu}$ (Gambar 4) maupun substrat Si (Gambar 3) tidak merata. Hasil lapisan pada titik tengah mempunyai lapisan $\mathrm{ZnO}$ pal- ing tebal dan hampir merata menutupi substrat dibandingkan pada titik kiri dan kanan lapisan.

\section{SIMPULAN}

Lapisan thin film $\mathrm{ZnO}$ berhasil dibentuk pada substrat $\mathrm{Si}$ dan $\mathrm{Cu}$ berbentuk pelangi tipis dengan bagian tengah lapisan putih dan tebal sedangkan bagian kiri dan kanan berbentuk lapisan-lapisan tipis seperti pelangi. Dari hasil SEM EDX dengan tiga titik yang berbeda (titik tengah, titik kiri dan titik kanan) menunjukkan bahwa lapisan $\mathrm{ZnO}$ tidak merata baik pada substrat $\mathrm{Si}$ maupun substrat $\mathrm{Cu}$ yang ditunjukkan dengan hasil perhitungan prosentase dari jumlah atom yang ada. Perlu dilakukan analisa lebih jauh pada bagian pelapisan yang membentuk pelangi dan untuk pembentukan lapisan yang homogen perlu dilakukan dengan memutar substat.

\section{Ucapan Terima Kasih}

Ucapan terimakasih ditujukan kepada RISTEK yang telah membiayai penelitian ini melalui program peningkatan Peneliti dan Perekayasa dan juga kepada Dr. Koo Hendrik Kurniawan yang telah mengijinkan dan memfasilitasi laser untuk melakukan penelitian ini.
[1] S. J. Pearton, D. P. Norton, K. Ip, Y. W. Heo, and T. Steiner, J. Vac. Sci. Technol. B 22, 932 (2004).

[2] Z. L. Wang, Mater. Today 7, 26 (2004).

[3] Takahashi, Kiyoshi; Yoshikawa, Akihiko; Sandhu, Adarsh, Wide bandgap semiconductors: fundamental properties and modern photonic and electronic devices (Springer.p. 357. ISBN 3540472347, 2007.)

[4] Hernandezbattez, A; Gonzalez, R; Viesca, J; Fernandez, J; Diazfernandez, J; MacHado, A; Chou, R; Riba, J. CuO, ZrO2 and $\mathrm{ZnO}$ nanoparticles as antiwear additive in oil lubricants, Wear 265: 422. doi:10.1016/j.wear.2007.11.013 (2008).

[5] Look, D. Recent advances in $\mathrm{ZnO}$ materials and devices, Materials Science and Engineering B 80: 383. doi:10.1016/S09215107(00)00604-8 (2001).

[6] Oh, Byeong-Yun; Jeong, Min-Chang; Moon, Tae-Hyoung; Lee, Woong; Myoung, Jae-Min; Hwang, Jeoung-Yeon; Seo, Dae-Shik, Journal of Applied Physics 99:124505. doi:10.1063/1.2206417 (2006).

[7] Kumar, S. Ashok; Chen, Shen-Ming, Analytical Letters 41 (2): 14158.doi:10.1080/00032710701792612 (2008).

[8] William C, Handbook of Semiconductor Silicon Technology (William Andrew Inc..pp. 349-352. ISBN 0815512376,1990). http://books.google.com/?id=COcVgAtqeKkC\&pg=PA351 $\& \mathrm{dq}=$ Czochralski + Silicon + Crystal+Face + Cubic. Retrieved 2008-02-24.

[9] William F. Smith, Javad Hashemi, Foundations of Materials Science and Engineering (McGraw-Hill Professional. p. 223. ISBN 0072921943, 2003).

[10] Bunshan, R.F., Deposition Technologies for Films and Coatings (New Jersey: Noyes Publications, 1994).

[11] Phipps, C., Laser Ablation and its applications (Springer Science + Business Media LLC, 2007). 